\title{
Metal Del Viento. Aproximación EXPERIMENTAL PARA LA COMPRENSIÓN DEL FUNCIONAMIENTO DE LAS WAYRAS ANDINAS
}

\author{
Florian Téreygeol ${ }^{1}$ y Pablo $\mathrm{Cruz}^{2}$
}

\section{$*$ Introducción}

Resumen

Los hornos andinos prehispánicos destinados a la fusión de minerales no ferrosos fueron objeto de varias investigaciones desde los años 1970 . Sus referencias son relativamente comunes en las fuentes documentales del siglo XVI. Ellas fueron retomadas in extenso por la mayoría de los autores que trataron sobre la antigua metalurgia de la plata en los Andes. Sin embargo, raros son los ejemplos de este tipo de estructura resultantes de excavaciones arqueológicas y la aproximación experimental es todavía reciente. En su conjunto estas pruebas tuvieron como objetivo comprender el funcionamiento de los hornos andinos conocidos como wayras y la manera en que se desarrollaron los procesos de fusión de minerales no ferrosos en los mismos. Las wayras experimentales fueron elaboradas a partir de datos arqueológicos obtenidos en sitios minero-metalúrgicos andinos del Departamento de Potosí (Bolivia) cronológicamente adscritos a los comienzos de la Colonia y en menor medida a tiempos prehispánicos.

Palabras claves: metalurgia andina - wayra - arqueología experimental horno prehispánico.

Abstract ferrous minerals have been the subject of many studies since the 1970s. References to the furnaces are relatively common in documentary sources from the 16th century, and have been widely cited by the majority of researchers investigating ancient silver metallurgy in the Andes. However, few examples of these structures have been found in archaeological

excavations, and experimental approaches are still incipient. These tests seek to understand the function of the Andean furnaces known as wayras, and the ways in which the processes of melting non-ferrous minerals occurred within them. The experimental wayras were developed based on archaeological data obtained from mining-metallurgical sites in the Department of Potosi (Bolivia), dating to the early Colonial Period and to a lesser extent pre-Hispanic times.

Key words: Andean metallurgy - wayra - experimental archaeology prehispanic furnace.

Recibido: julio 2014. Aceptado: octubre 2014.
Los hornos andinos prehispánicos destinados a la fusión de minerales no ferrosos fueron objeto de varias investigaciones desde los años 1970. Sus referencias son relativamente comunes en las fuentes documentales del siglo XVI. Ellas fueron retomadas in extenso por la mayoría de los autores que trataron sobre la antigua metalurgia de la plata en los Andes (Bargallo 1968; Petersen 1970; Oehm 1984; Arduz Eguia 1997; Van Buren y Mills 2005; Téreygeol y Castro 2008; De Nigris y Puche Riart 2011; Téreygeol y Cruz 2012a y b, entre otros). Sin embargo, raros son los ejemplos de este tipo de estructura resultantes de excavaciones arqueológicas y la aproximación experimental es todavía incipiente (Van Buren y Mills 2005; Cohen, Rehren y Van Buren 2008; Van Buren y Cohen 2010; Téreygeol y Cruz 2012a y b).

En este trabajo damos cuenta de las recientes pruebas realizadas en hornos andinos experimentales con ventilación natural y los resultados alcanzados en las mismas. Tales pruebas se desarrollaron en la localidad de Tilcara (Jujuy, Argentina) en 2014, y completaron una serie de pruebas desarrolladas anteriormente en la plataforma experimental de Melle (Poitou-Charentes, Francia) (Figura 1). En su conjunto estas pruebas tuvieron como objetivo comprender el funcionamiento de los hornos andinos conocidos como wayras y la manera en que se desarrollaron los procesos fusión de minerales no ferrosos en los mismos. Las wayras experimentales fueron elaboradas a partir de datos arqueológicos obtenidos en sitios minero-metalúrgicos andinos del Departamento de Potosí (Bolivia) cronológicamente

1 CNRS, UMR 5060 IRAMAT-LMC, Belfort, FRANCE. Email: tereygeol@cea.fr

2 CONICET, Instituto interdisciplinario Tilcara, Facultad de Filosofía y Letras, Universidad de Buenos Aires. ARGENTINA. Email: saxrapablo@gmail.com 


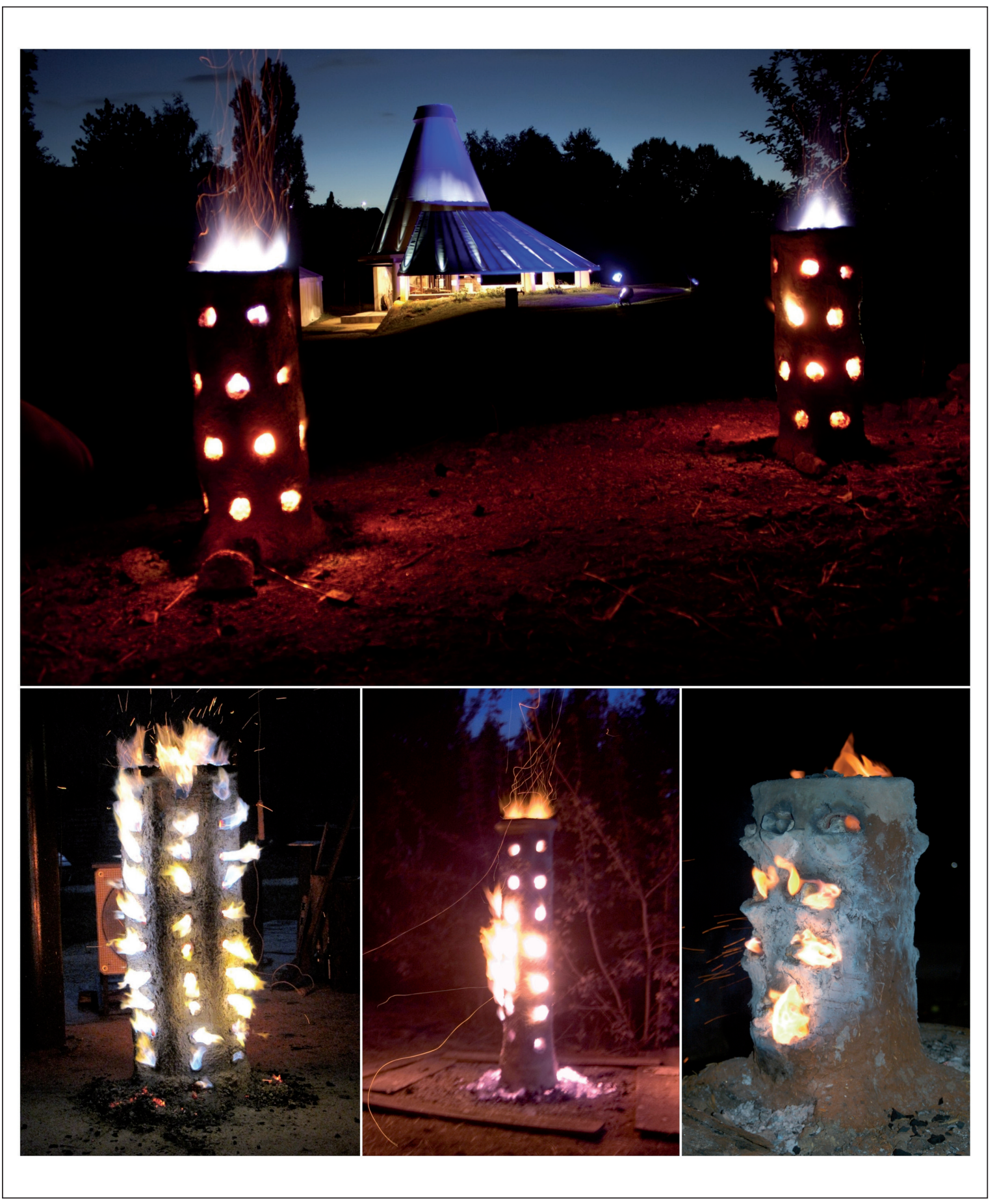

Figura 1. Diversas wayras experimentales elaboradas en la plataforma experimental de Melle (Francia). 
adscritos a los comienzos de la Colonia y, en menor medida, a tiempos prehispánicos.

\section{* Un rompecabezas de informaciones HISTÓRICAS Y ARQUEOLÓGICAS}

Los hornos de viento andinos provocaron una gran fascinación entre los europeos establecidos en los Andes durante los primeros años de la Colonia, entre finales del siglo XVI y comienzos del XVII. Sus referencias en las fuentes son numerosas y diversas, y se concentran principalmente en torno a la metalurgia de Potosí, el principal yacimiento de plata de la región, y del planeta. Tal fascinación resultó tanto de la tecnología particular manifiesta en este tipo de hornos, desconocida en el Viejo Mundo, como de las incapacidades que tenían los propios españoles para procesar eficientemente los minerales ricos en plata de los Andes con la tecnología europea. Las descripciones sobre las wayras disponibles en las fuentes coloniales no se encuentran, sin embargo, a la misma altura del renombre que alcanzaron. Entre ellas sobresalen la de Cieza de León (1550), ${ }^{3}$ la más temprana, la de Baltazar Ramírez (1597), ${ }^{4}$ la más detallada, y la del Padre Álvaro

3 “...En este Potosí, aunque por muchos se ha procurado, jamás han podido salir con ello; la reciura del metal paresce que lo causa, ó algun otro misterio; porque grandes maestros han intentado, como digo, de los sacar confuelles, $y$ no ha prestado nada su diligencia; $y$ al fin, como para todas las cosas puedan hallar los hombres en esta vida remedio, no les faltó para sacar esta plata, con una invencion la mas extraña del mundo, y es, que antiguamente, como los ingas fueron tan ingeniosos en algunas partes que les sacaban plata, debia no querer correr con fuelles, como en esta de Potosí, y para aprovecharse del metal hacian unas formas de barro, del talle y manera que es un albahaquero en España, teniendo por muchas partes algunos agujeros ó respiraderos. En estos tales ponian carbon, y el metal encima; y puestos por los cerros ó laderas donde el viento tenia mas fuerza, sacaban dél plata, la cual apuraban y afinaban después con sus fuelles pequeños o cañones que soplan..." / "...Llaman a estas formas Guayras. Y de noche hay tantas dellas por todos los campos y collados que parecen luminarias. Y en tiempo que hace viento recio, se saca plata en cantidad: quando el viento falta, por ninguna manera pueden sacar ninguna..." Cieza de León (1862 [1553]: 442).

4 “...El modo antiguo para beneficiar los metales antes de que se introdujese el azogue, era una fundición en hornos de viento, los cuales los indios llamaban guairas. Estos son hornos portátiles de forma de una cajuela de barro crudo de un dedo de grueso. Tiene una vara y poco mas de alto y una tercia en ancho en el pie; de allí va ensanchando hasta media vara en lo más alto. Está lleno de ojos o bocas por la delantera, por donde recibe el viento con que se enciende y funde, y en los lados y espalda tiene otros ojos pocos y pequeños por donde sale el humo. Estos hornos ponen
Alonso Barba (1640), ${ }^{5}$ la más reproducida por estar acompañada de un dibujo. Por su detalle, se destaca igualmente un dibujo anónimo del siglo XVI titulado “...Estos yndios están guayrando...", el cual muestra un grupo de operarios indígenas manipulando estos hornos sobre la cresta de un cerro en Potosí. ${ }^{6}$ Síntesis de estas referencias coloniales se encuentran en la bibliografía antes citada, en particular el trabajo pionero de Modesto Bargalló (1968).

Si bien se observa una concordancia tipológica en la mayoría de las descripciones coloniales, ellas sugieren que existieron al menos tres modelos o tipos de wayras: las wayras propiamente "indígenas" construidas en cerámica a modo de un "albacahaquero" (maceta), 7 las wayras construidas en piedra, ${ }^{8}$ igualmente indígenas, y las wayras "mejoradas" por los españoles, elaboradas también en cerámica. ${ }^{9}$ La "invención" de esta última es atribuida a Juan

los indios en lugares altos y exentos, donde les da el viento con libertad; cuando el viento es escaso se suben a los cerros y cuando es mucho se bajan a lo llano... Funden en estos hornos de día y de noche, como tienen el viento. Hínchanlos de carbón y pónenles fuego y en lo alto echan el metal. Al pie del horno tienen puesta una cazuela de barro...". Descripción del reino del Perú, del sitio, temple, provincias, obispados y ciudades de los naturales, de sus lenguas y trajes. Mss, México, 1597 en: Bargalló (1968: 33), Historia de la Ciencia y la Tecnología: La "Guayra", horno de fundición del Antiguo Perú, estudio de las referencias de los cronistas, Ciencia Vol. 26: 31-38. México. Patronato de Ciencia.

5 "...Los naturales de esta tierra, como no alcanzaron el uso de nuestros fuelles, usaron para sus fundiciones los hornos que llaman guayras, y oy los usan todavía en esta Villa Imperial y otras partes. Son semejantes a los castellanos dichos; diferéncianse en que por todas las partes están llenos de agujeros por donde entra el ayre quando el viento sopla, tiempo en que sólo pueden fundir. Salen por la parte de abaxo de cada uno de estos agujeros unas como orejas pequeñas, en que se sustenta con carbón por la vanda de afuera, para que entre el ayre caliente. Pónense en lugares altosy donde corra el viento de ordinario..." Barba 1770 [1640]: 133.

6 "Éstos yndios están guayrando". Dibujo anónimo del siglo XVI. Atlas of the Sea Charts, The Hispanic Society of America.

7 Ver citas anteriores.

8 Por ejemplo, Capoche: “...Y a las fundiciones que era menester más fuerza, aprovechábanse del mismo viento, haciendo en el campo, en las partes altas, unos hornillos de piedras sueltas, puestas unas sobre otras sin barro, huecas a manera de unas torrecillas, tan altas como dos palmos. $Y$ ponían el metal con estiércol de sus ganados y alguna leña, por no tener carbón; e hiriendo el viento por las aberturas de las piedras se fundía el metal...". Capoche 1959 [1585]: 110).

9 "...Y el tiempo que es maestro e inventor de las artes, enseñó a hacer de barro, por industria de Juan de Marroquí, natural de (...) unas formas de barro de la hechura de esta demostración que llamaron guairachina 
de Marroquí, un minero español residente en Potosí (Capoche 1959 [1585]: 110). Al mismo tiempo, algunas fuentes señalan que las wayras construidas en arcilla pudieron ser fijas, o bien, móviles o portátiles. ${ }^{10}$ Como lo veremos más adelante, se trata de un aspecto importante a tener en cuenta en su correlato con el registro arqueológico y las pruebas experimentales desarrolladas. La tecnología de la wayra fue empleada masivamente hasta comienzos de los años 1570, momento en que se implementa en Potosí el proceso de amalgamación por mercurio que condujo a su progresivo reemplazo. Otro aspecto relevante sobre la tecnología de este tipo de hornos utilizados en establecimientos de comienzo de la Colonia, señalada tanto por las fuentes documentales como por el registro arqueológico, es que la misma reposó exclusivamente en los saberes y maestría de especialistas indígenas, los famosos "yanaconas guayradores". Al respecto, un documento de $1571^{11}$ señala que estos especialistas llegaron a Potosí desde 77 localidades repartidas en los Andes Centrales, significativamente 49 de ellas ubicadas en el Collao. ${ }^{12}$ Otro documento señala que en 1575 , es decir a pocos años de establecerse el proceso de amalgamación, continuaban desempeñándose en Potosí como guayradores unas 536 personas (Escobari 2011). La participación de estos especialistas se vio justificada por lo complejas que resultaban las prácticas metalúrgicas, desde la selección del mineral hasta el manejo de las temperaturas y los vientos.

o guaira que hasta hoy conservan y usan..." Con respecto a su forma el mismo autor señala: "es tan alta como una vara común con cuatro ángulos o esquinas, prolongadas, casi cuadrada abierta por arriba; tiene hechos por sus cuatro lienzos o haces aberturas o ventanillas por que por ellas haga más efecto el viento; tiene suelo donde remata, viniendo disminuiendo desde lo alto a lo bajo, con alambique por donde destila el metal que se funde, está firme, levantada del suelo sobre un asiento a manera de pedestal, vara y media, y dos, en alto para que la señoree más el viento donde parecellamarse guaira [que] en esta lengua significa viento..." Capoche 1959 [1585]: 110 .

10 “...templado así el metal lo fundían en unos hornillos portátiles, a manear de nafes de barro...". Garcilazo de la Vega 1992 [1603]: 206).

${ }^{11}$ Orden que se dio en Potosí para que los indios no hiciesen fundiciones de plata y nombramientos de alcaldes que se hicieron en varias doctrinas. Gerónimo Luís de Cabrera, Potosí 15 de marzo de 1571 . BN/Ms 3040 fs. 167 r-169v.

${ }^{12}$ La participación de oriundos del Collao en la antigua minería y metalurgia andina es abordado en un trabajo actualmente en evaluación en Estudios Atacameños: "Yanaconas del rayo. Reflexiones en torno a la producción de metales en el espacio surandino (Bolivia, siglos XV-XVI)", Cruz, P. y F. Téreygeol 2014.
El propio Diego Gualpa, súbdito inka al servicio de los españoles de Porco y "descubridor" oficial del mineral de Potosí, sobre quien tratamos ampliamente en otros trabajos (Cruz y Absi 2008, Cruz 2009), ilustra las dificultades que tuvieron los españoles cuando intentaron fundir el mineral por él descubierto. ${ }^{13}$ Finalmente, otro aspecto de importancia, fue la dimensión mágico-religiosa que tuvo la producción de metales en tiempos prehispánicos (Bouysse-Cassagne 2005, 2008), la cual sin duda se mantuvo vigente durante los primeros años de la Colonia, siendo las minas, los minerales, las wayras y los metales objeto de veneración por parte de los indígenas andinos. ${ }^{14}$

A pesar de las numerosas referencias documentales, a la fecha no se hallaron registros materiales de antiguas wayras, sean éstas históricas o etnográficas, intactas o parcialmente intactas..$^{15} \mathrm{~A}$ la fecha, sólo se dispone de los escasos dibujos coloniales conocidos y de una antigua fotografía publicada en el libro de Robert Peele (1894), la cual muestra un indígena posando junto a dos wayras. No sabemos, sin embargo, si tales wayras fueron construidas y utilizadas con fines metalúrgicos, o si se trata, más bien, de reconstrucciones elaboradas a los fines de la publicación. Por su parte, la identificación de antiguas wayras a partir de sus fragmentos arqueológicos no resulta una tarea sencilla, principalmente dadas sus similitudes con otros tipos de hornos metalúrgicos igualmente con reactores tubulares o cilíndricos pero que funcionaron con una ventilación forzada (sopladores, fuelles). Dos criterios resultan esenciales para poder identificar certeramente una wayra. Por

13 “...Cuando este indio vido que no quiso llegar el español Olmedo al lugar do había sacado el metal que le había mostrado, dijole en Porco: "toma la mitad deste metal y fúndelo", y el indio se quedó con la otra parte; y fundiéndolo el dicho Álvaro Olmedo, como cosa que no tenía Dios criado para él, se le fue en humo todo, y el indio Gualpa fundió su parte, y echando en ello algún soroche, sacó tanta cantidad de plata como metal había fundido..." de la Fuente Sanct Ángel (1965 [1572]: 330).

14 “...Lo mismo solian hazer en las minas que llaman copa que adoraban y reberençiavan a los metales que llaman mama y a las piedras de los metales que llaman corpas. Adoravanlas vezandolas, y haciendo diferentes ceremonias y a las pepitas de oro y oro en polvo y la plata, y las guayras donde se funde la plata..." Murúa (2004 [1590]: Ch 4.9: 101). La transcripción es nuestra.

${ }^{15}$ Durante las investigaciones de campo en el área surandina hemos compilado muchas indicaciones de sitios con wayra aun en pie. Aunque en ningún caso estas indicaciones pudieron ser corroboradas, consideramos como muy probable que en el futuro puedan hallarse restos conservados de este tipo de hornos. 


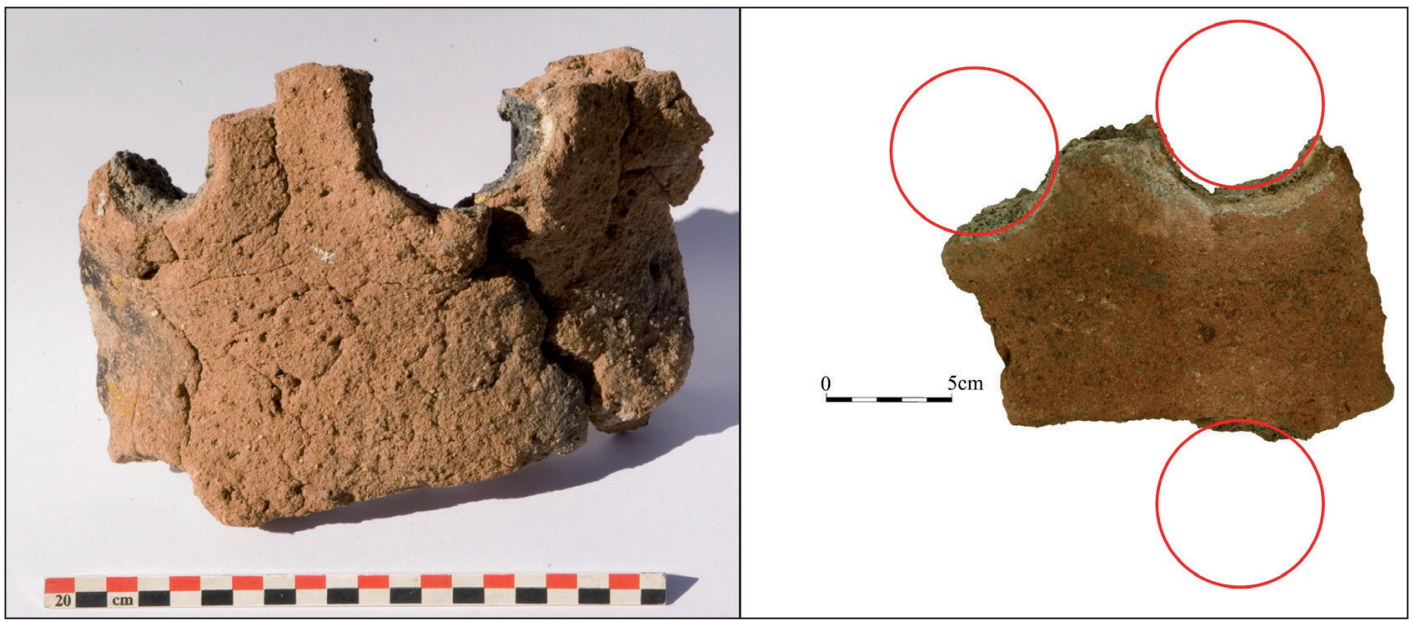

Figura 2. Fragmentos de wayras arqueológicas hallados en sitios metalúrgicos de Potosí.

un lado, la presencia de fragmentos de paredes tubulares con orificios de ventilación natural. Por el otro, la ubicación específica de dichos fragmentos en espacios expuestos a la acción de fuertes vientos. Los registros materiales de estos hornos son escasos y fueron principalmente hallados en la región del departamento de Potosí en el sur de Bolivia, en centros minero-metalúrgicos como Potosí y Porco (Figura 2). A priori, los restos identificados en estos centros se ubicarían cronológicamente en los comienzos de la Colonia, aunque no se puede descartar que algunos sean anteriores, o bien, posteriores. En Potosí, donde pocos años después de su fundación (1545) llegaron a funcionar 6497 wayras según Capoche (1959 [1585]: 111), se identificaron nueve sectores metalúrgicos con restos de estos hornos, todos ellos localizados sobre las cumbres y crestas que bordean esta ciudad. Entre estos espacios destaca el sitio Juku Huachana donde se hallaron 60 estructuras circulares y rectangulares que sirvieron como base para los hornos (Figura 3). Una muestra de restos de paredes de hornos arqueológicos procedentes de este sitio fue estudiada en laboratorio. En primer lugar se confirmó el uso de los fragmentos seleccionados en una cadena operativa metalúrgica. Una comparación entre las representaciones y descripciones coloniales de estos hornos con los fragmentos arqueológicos hallados, confirmó una correspondencia entre ambos. Asimismo, varios elementos de estos fragmentos evidencian un contacto de las paredes con altas temperaturas, las cuales alcanzaron entre 720 y $1200{ }^{\circ} \mathrm{C}$. Las gotas de metal halladas en los fragmentos muestran que los mismos estuvieron en contacto directo con metales en estado líquido.
Además, el espesor de la capa vitrificada de (0,2 - 2mm) indicó que la utilización fue intensa y no puntual. Por otra parte, las paredes revelaron una morfología de los hornos particularmente adaptada a la metalurgia con granos gruesos y espesores entre 1,5 y $3 \mathrm{~cm}$, los cuales permiten una gran resistencia a los choques térmicos a altas temperaturas. Todos los fragmentos fueron asociados con una metalurgia de plata dada la presencia de este metal en las partes vitrificadas, o bien en forma de gotas metálicas cuyas proporciones revierten una importancia significativa. Esta significante proporción de plata en las paredes revela una pérdida importante durante los procesos de fundición. Finalmente, otro aspecto relevante puesto en evidencia en sitios como Juku Huachana, es que la selección del mineral a fundir se efectuaba en el mismo espacio metalúrgico. En concordancia con las fuentes, el mismo sugiere que los saberes metalúrgicos se encontraban en manos de especialistas, y que los mineros no participaron en las decisiones productivas.

En Porco, Van Buren y Mills (2005 y otros) señalaron la existencia de varios espacios metalúrgicos con restos de antiguas wayras, igualmente localizados en puntos elevados del relieve. Por su parte, testimonios de hornos metalúrgicos prehispánicos del tipo wayra fueron registrados en dos sitios arqueológicos cercanos al salar de Uyuni: Jirira Vinto y Pulacayo 050. En el primero, ubicado en la ribera norte del salar (Daniel Campos, Oruro), asociado con una pucará fechada entre el 1300 y 1419 de nuestra era $(95 \%, 580+/-30 \mathrm{AP})$, los fragmentos de wayra hallados 


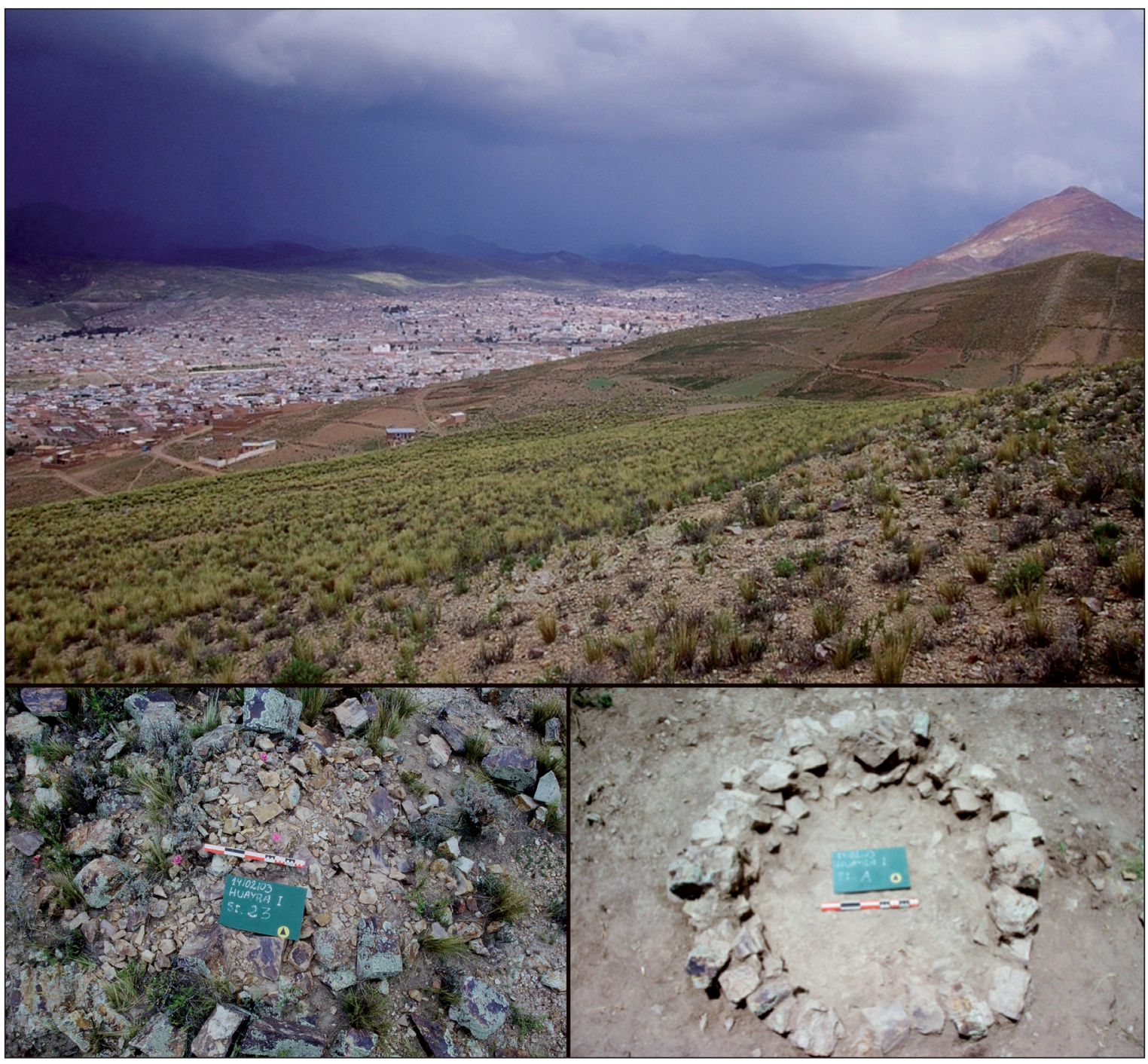

Figura 3. Sitio Juku Huachana, Potosí. Fotografías del sitio (fondo: ciudad de Potosí y Cerro Rico), y de estructuras asociadas con la fundición con wayras.

muestran una significativa presencia de cobre. Un aspecto significativo, pero que no resulta suficiente como para afirmar que fueron utilizadas exclusivamente para el procesamiento de este mineral. El segundo sitio, ubicado a $15 \mathrm{~km}$ al este de la localidad de Uyuni (Antonio Quijarro, Potosí), es un importante establecimiento metalúrgico prehispánico cuya cronología multicomponente se extiende entre los siglos IX y XIV (Cruz 2010; Lechtman, Cruz y McFarlane 2011). Hornos del tipo wayra fueron igualmente señalados en otros sitios prehispánicos del espacio surandino, entre ellos Miño Collahuasi (Salazar, Berenguer y Vega 2013: 94) y Viña del Cerro en el norte de Chile (Niemeyer, Cervellino y Muñoz 1983; Niemeyer 1986: 178), y Quillay en el norte de Argentina (Raffino et al. 1996), todos ellos relacionados con la ocupación inkaica de la región. En el segundo sitio, las estructuras identificadas guardan una sorprendente similitud con aquellas registradas en el establecimiento de Juku Huachana de Potosí. En Quillay, sin embargo, tanto la localización del sitio como la propia morfología de los hornos registrados -recientemente objeto de estudios detallados (comunicación personal Josefina Spina)-, sugiere que no se trataría del mismo tipo de estructura que las 
wayras "altoandinas", principalmente al no comportar los múltiples orificios de ventilación natural.

Así, y de manera general, los fragmentos de wayras hallados en sitios del sur de Bolivia permitieron fijar algunas pautas básicas para la construcción de los modelos experimentales. Por un lado, las wayras identificadas tuvieron una forma cilíndrica, y sabemos que al menos algunas de ellas fueron construidas utilizando pequeños bloques o panes rectangulares de arcilla. Se trata de un procedimiento coherente con las limitaciones ambientales de los sitios donde fueron emplazadas para su funcionamiento. Por el otro, todas las paredes de wayras halladas presentaban una cocción incompleta, aspecto que señala la ausencia de una etapa previa de horneado del horno. Es decir, las wayra fueron construidas poco tiempo antes de su puesta en funcionamiento. Como lo veremos más adelante, esta condición no resulta contradictoria con las informaciones que hacen referencia a wayras móviles o portátiles. Finalmente, y de manera algo intrigante, en ninguno de los fragmentos de pared de wayra con orificios de ventilación natural hallamos rastros de labios exteriores pronunciados, tal como lo señalan las descripciones y dibujos coloniales. Es posible que las descripciones de estos atributos hayan sido exageradas.

\section{* Los hornos experimentales y las pruebas METALÚRGICAS}

La cuestión de la experimentación sobre este tipo de horno plantea varios problemas. En primer lugar, ¿cómo reconstituir los reactores ante la falta de evidencias arqueológicas sustanciales? Las descripciones que ofrecen los autores coloniales dejan un importante margen de vaguedad sobre las dimensiones de estos hornos (Van Buren 2005). Visiblemente utilizado para la metalurgia de diferentes minerales no ferrosos, la estructura presenta un carácter proteiforme que limita la explotación de las informaciones brindadas por las fuentes. Es más, a pesar del estudio del material arqueológico concerniente a una zona acotada y una metalurgia específica, aquella del plomo argentífero, no es todavía posible definir un tamaño preciso para este tipo de horno (Téreygeol y Cruz 2012). Segunda importante limitación, el modo operato- rio pone en juego la fuerza del viento como factor determinante, tal como lo atestiguan a la vez la composición del nombre vernacular wayra (guayra, huaira, guayrachina, etc., del quechua: viento), y las relaciones hechas por los autores coloniales. En tercer lugar, esta metalurgia se desarrolló en lugares altos y con una atmosfera rarificada. Los primeros ensayos que realizamos sobre este tipo de hornos tuvieron lugar en Europa sobre la plataforma experimental de Melle (entre 2006 y 2010). Ellos no dieron resultados positivos y permitieron comprender como fabricar eficazmente una wayra. Con la intención de sobrepasar los límites de la plataforma de Melle y responder nuestras interrogantes sobre el rol del viento en el rendimiento de estos hornos, se decidió localizar entonces las pruebas experimentales en el ambiente histórico de las wayras. Las pruebas se llevaron adelante durante los meses de Abril-Mayo 2014 en la localidad de Tilcara (Provincia de Jujuy, Argentina). Ellos se desarrollaron sobre una meseta de altura situada por encima del pueblo, en proximidades del camino que conduce al paraje conocido como "Garganta del Diablo" (S 233 35'12,8" WO $65^{\circ} 23^{\prime} 14,4^{\prime \prime}$, altura: $2759 \mathrm{~m}$ ). En este lugar la presión atmosférica es equivalente a 7200 Pa y tiene un déficit de aire en relación con el nivel del mar en torno al $28 \%$. El interés que porta el viento en el funcionamiento de este tipo de hornos condujo a tomar varias medidas de su velocidad a fin de compararlas con los datos conocidos en los sitios de Potosí y Melle. En el sitio Juku Huachana, en Potosí, registramos una velocidad de los vientos cercana a los $19 \mathrm{~m} / \mathrm{seg}$ Inversamente, en Melle, donde tuvieron lugar los primeros ensayos experimentales, la fuerza máxima del viento no sobrepasó en ningún momento los 5,5m/seg (Téreygeol 2009: 72). En Tilcara, las primeras medidas del 15/04/2014, tomadas alrededor de las $15 \mathrm{hrs}$, muestran un viento que evolucionó en dirección sur-norte entre 4 y $11 \mathrm{~m} / \mathrm{seg}$. El 17/04/2014 por la mañana (10 hrs $20 \mathrm{~min}$ ), el viento norte-sur corrió entre 2 y $4 \mathrm{~m} / \mathrm{seg}$. El 18/04/2014, el viento sur-norte se incrementó durante la tarde, pasando de 4-6 m/ seg a 7-9 m/ seg. A partir de las 17 hrs, el viento fue sostenido, y cerca de las 19 hrs, después de la caída del sol, cayó rápidamente. Es decir, de manera general, la velocidad del viento en Tilcara resultó inferior de aquella observada en Potosí en un factor de 2 a 5 , pero fue en todos los casos superior a la registrada en Melle. Las limitaciones de tiempo y recursos impusieron llevar adelante las pruebas independientemente de la fuerza del 


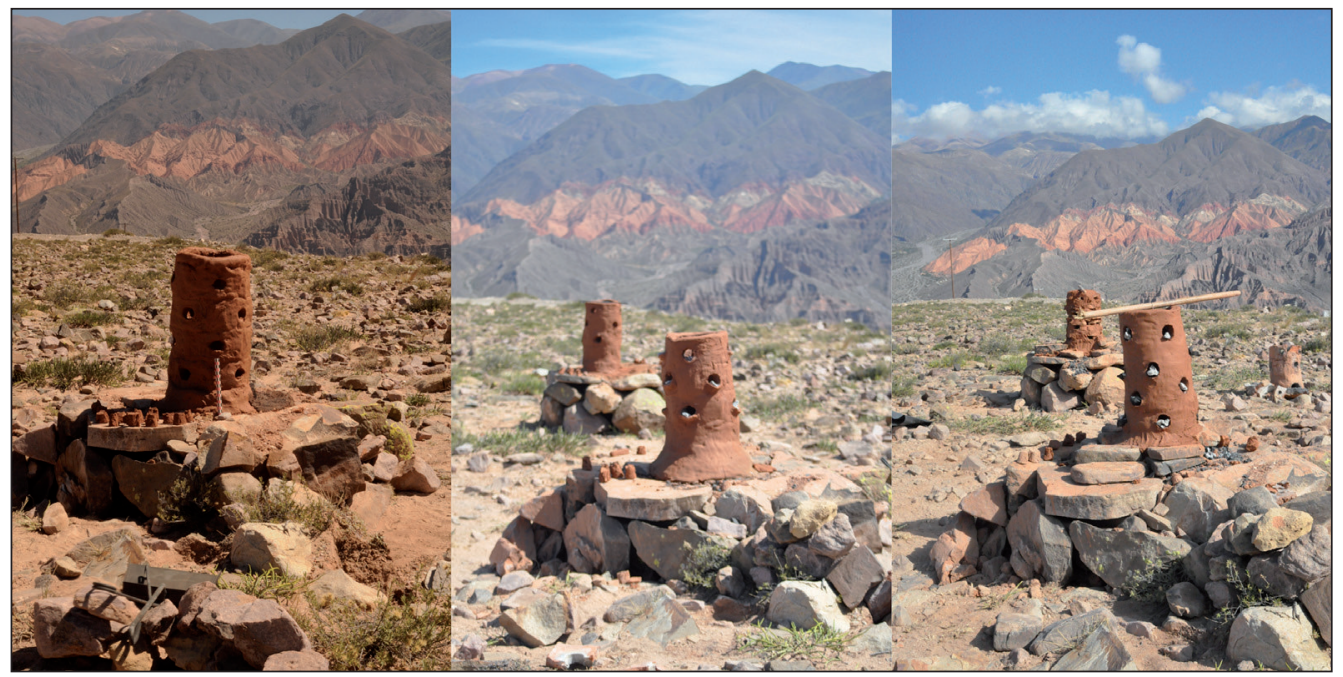

Figura 4. Wayras 1, 2 y 3

viento, un aspecto central que influyó en la calidad de los resultados obtenidos. En contraposición, la dirección aleatoria del viento no impactó negativamente en la experiencia dado que, visiblemente, este tipo de horno fue concebido tomando en cuenta esta variable, razón por la cual presentan orificios de ventilación sobre toda la superficie de la columna de reducción.

\section{La construcción de los modelos experimentales}

Los materiales utilizados en las pruebas experimentales forman el clásico tríptico metalúrgico: arcilla, mineral y combustible. La arcilla fue tomada en cercanías de Tilcara, en la ribera del río Grande que atraviesa la Quebrada de Humahuaca, y puesta a decantar durante una semana. Esta fue preparada por lotes de 51 a los que se les agregó 11 de arena fina ( $\mathrm{mm}$ ). Una vez la arcilla amasada y "golpeada" se fabricaron pequeños panes rectangulares con la ayuda de un molde de 15 × 10 x 2,5 cm. Para la primera prueba $\left(\mathrm{W}_{1}\right)$, los panes fueron fabricados el día anterior a la puesta en funcionamiento del horno. Frente a la rapidez de secado y a la escasa humedad ambiental, los ladrillos usados en las pruebas posteriores fueron hechos en el momento en que se construyeron las wayras en el mismo sitio de fundición, sirviendo la wayra $\mathrm{W}_{4}$ para las pruebas 6 y 7 . Estos panes elaborados en el sitio fueron calibrados a mano sin uso del molde. De manera general la arcilla tuvo una retractación del 5\% al término del ciclo de secado y cocción.
Por su parte, el mineral utilizado fue proporcionado por la mina El Aguilar. Un análisis por DRX permitió confirmar su composición. Se trata de un mineral de plomo, galena (PbS), con otro componente mayor: calcopirita $\left(\mathrm{CuFeS}_{2}\right)$. En algunos lotes se detectaron igualmente esfalerita $(\mathrm{ZnS})$ y pirita $\left(\mathrm{FeS}_{2}\right)$, pero en cantidades limitadas. El mineral utilizado provino visiblemente de una veta relativamente importante de la mina, comportando poco material de caja. El mineral se pudo triturar fácilmente hasta alcanzar una granulometría de tipo "grano de café" (10-15 mm) para el conjunto de los experimentos, a excepción de $\mathrm{W}_{1}$ y $\mathrm{W}_{3}$, en los cuales se utilizó el mineral en estado de polvo. Para Wi, 3 cargas de 300 gr fueron volcadas en el horno, mientras que para el resto las cargas fueron cada una de $1 \mathrm{~kg}$, completando en cada experimento $3 \mathrm{~kg}$, salvo en $\mathrm{W}_{7}$, donde el total fue de $2 \mathrm{~kg}$.

Finalmente, el combustible empleado fue un carbón muy denso y duro (quebracho, Schinopsis lorentzii). El proceso de pirolisis fue largo - salvo las cortezas que se disgregaron fácilmente-, el carbón utilizado produjo brasas resistentes y poca cantidad de cenizas. A los fines de las pruebas el carbón fue calibrado en un tamaño cercano al de una nuez $(2,5-3,5 \mathrm{~cm})$. Un dato a la vez relevante y sorprendente por la poca cantidad: el consumo de combustible se limitó a aproximadamente $6 \mathrm{~kg}$ por cada prueba realizada. 


\section{Los reactores}

En total se elaboraron seis wayras (Figura 4). Cinco de ellas fueron fabricadas en arcilla y una con piedras. Todas ellas presentan características comunes que resumimos aquí. Las wayras fueron colocadas sobre una pequeña plataforma o podio de piedra, de $30 \mathrm{~cm}$ de altura y $80 \mathrm{~cm}$ de diámetro. Las columnas de reacción tuvieron $50 \mathrm{~cm}$ de altura por un diámetro de $15 \mathrm{~cm}$, es decir un volumen estimado de $8000 \mathrm{~cm}^{3}$, a excepción de W8 que tuvo una altura de $60 \mathrm{~cm}$ y un volumen estimado de $9600 \mathrm{~cm}^{3}$. Las puertas de vaciado fueron colocadas hacia el norte, en contraviento. Estas aperturas tuvieron $7 \mathrm{~cm}$ de largo por $5 \mathrm{~cm}$ de alto. Por su parte, los orificios de ventilación, con un diámetro de $5 \mathrm{~cm}$, fueron ubicados en todo el contorno del reactor. Las wayras fueron construidas con 16 panes sobre una base de arcilla, salvo W8 que insumió 20 panes. En todas las wayras se colocaron sensores de temperatura por termocuplas en el interior de los reactores, ellas fueron dispuestas a $10 \mathrm{~cm}$ de altura sobre la pared expuesta al viento.

Wayra 1: en este primer modelo se incluyó una fina capa de arcilla con carbón en el fondo del horno. La débil interacción entre la arcilla y el plomo, así como en el mantenimiento del plomo líquido al final de la operación nos condujo a no renovar este componente. La wayra fue construida durante la mañana y puesta en funcionamiento ese mismo día.

Wayras 2 y 3: en razón de que el fondo del horno W1 no había alcanzado una temperatura óptima al final de la operación, se decidió suprimir el primer rango de orificios de ventilación sobre la base del horno. Las wayras $\mathrm{W}_{2}$ y W3 solamente tuvieron 12 orificios de ventilación. Ambas wayras fueron construidas el día anterior a su puesta en funcionamiento, razón por la cual ellas tuvieron un tiempo de secado de $30 \mathrm{hrs,} \mathrm{netamente} \mathrm{superior}$ a las 6 hrs de la prueba anterior. Por otro lado, antes de su puesta en funcionamiento se forzó el secado de los hornos mediante la inclusión de brasas de carbón, produciendo en el interior una temperatura que fue aumentando progresivamente desde los $50^{\circ} \mathrm{C}$ a los $100{ }^{\circ} \mathrm{C}$. Las fisuras de retractación de la arcilla que aparecieron en el exterior de los hornos fueron sistemáticamente selladas.

Wayras 4, 6 y 7: se trata de la misma wayra utilizada tres veces. Como resultado de la operación precedente se pudo constatar que la supresión del primer rango de orificios de ventilación tuvo como consecuencia la

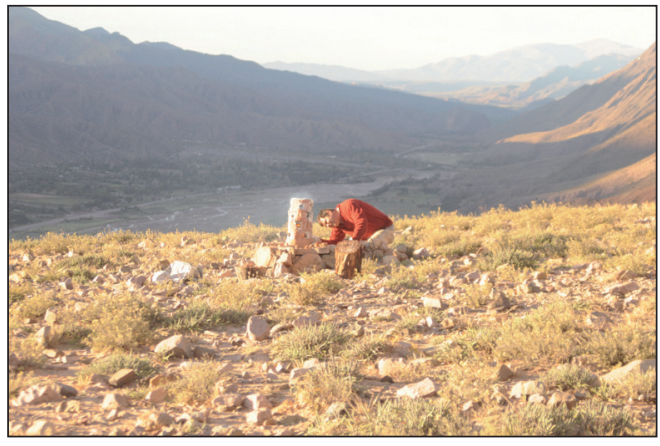

Figura 5. Wayra 1 en funcionamiento.

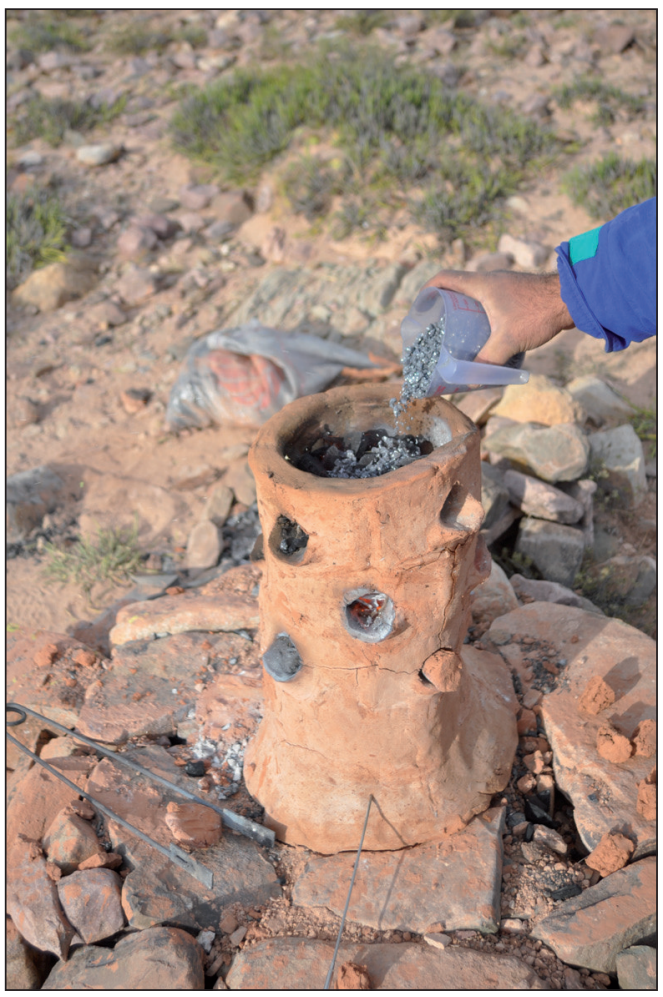

Figura 6. Carga de mineral en la wayra 2.

ampliación de un espacio con temperatura inferior a la necesaria. Por tal razón se retomó el modelo de la wayra 1. A fin de limitar la zona fría, y sobre la base del funcionamiento de los hornos precedentes, se implementó una corona de piedras en la base que limitó la cantidad de arcilla utilizada. Una menor cantidad de arcilla significa una menor cantidad de evaporación de agua. La wayra 4 fue construida el día anterior a su utilización y contó con 


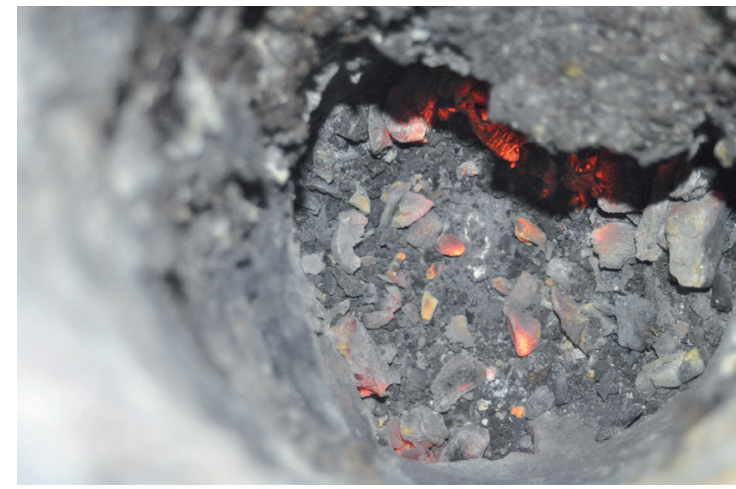

Figura 7a. Plomo en el fondo de la wayra 2.

el mismo tiempo y proceso de secado que $\mathrm{W}_{2}$ y $\mathrm{W}_{3}$. Una segunda sonda con termocupla fue colocada en el mismo nivel que la primera, pero en el lado opuesto, en contraviento, a fin de apreciar el gradiente térmico del interior del horno, a $10 \mathrm{~cm}$ del fondo.

Wayra 5: se trata de un modelo particular, construido con piedras unidas con arcilla. Su reconstitución se fundamenta exclusivamente en informaciones brindadas por Luis Capoche (1959 [1585]: 110) y otros autores coloniales. Los orificios de ventilación fueron rectangulares, en lugar de circulares como las otras wayras, y más estrechos ( 4 × 2 $\mathrm{cm})$. Por tal razón, y a fin de compensar las superficies expuestas al viento, ellos fueron dos veces más numerosos.

Wayra 8: se trata de un modelo igualmente particular, elaborado con posterioridad a los anteriores, el 18/o6. Se trata de un horno construido sobre una base transportable en hierro (arado de disco con bordes), de acuerdo con las informaciones históricas sobre wayras móviles y siguiendo el dibujo de Barba, donde el reactor se encuentra emplazado en una especie de contenedor en cerámica. La razón de utilizar una base en hierro y no en arcilla fue la de limitar las posibles roturas por choque térmico y evaporación observadas en las paredes de los hornos. Asimismo, a fin de potenciar el proceso metalúrgico, se aumentó la altura del reactor con un nivel suplementario con orificios de ventilación. El horno fue construido y secado en la localidad de Tilcara y posteriormente transportado al espacio de experimentación.

\section{Desarrollo de las pruebas}

Prueba Wi: la primera prueba fue llevada a cabo el 18/04. A las 16 hrs 30 min se procedió a llenar el horno

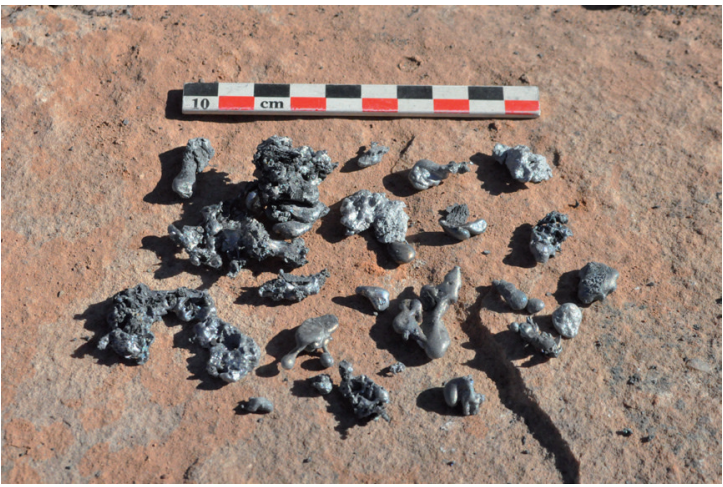

Figura $7 \mathrm{~b}$. Plomo recuperado en wayra 2

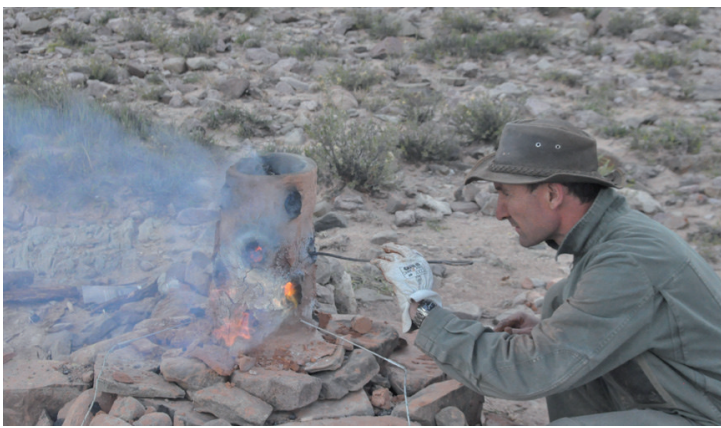

Figura 8. Wayra 4 en funcionamiento.

con carbones calientes, constatando en menos de media hora varios desprendimientos de arcilla en las paredes interna y externa. En el exterior, los desprendimientos se localizaron en el lado protegido del viento. A las 17 hrs el horno alcanzó una temperatura de $900{ }^{\circ} \mathrm{C}$ en su base, y a las 17 hrs 15 min se depositó una primera carga de mineral (300 gr). Frente a la velocidad de descenso del mineral, principalmente debido a su tamaño reducido, las otras dos cargas fueron operadas a las $17 \mathrm{hrs} 25$ y 17 hrs 30. Los orificios de ventilación dejaron expuestos carbones en estado "blanco refulgurantes" lo cual indica una temperatura entre 1100 y $1200{ }^{\circ} \mathrm{C}$. Sin embargo, el procesamiento del mineral fue demasiado rápido no logrando transformarse correctamente (Figura 5). Sólo se pudo constatar algunas gotas de plomo adheridas a la pared a nivel de los orificios, concentrándose el mineral por debajo de la primera línea de orificios, lo cual trajo como consecuencia una limitación de la temperatura y de la combustión de los carbones que se hallaban por debajo. No liberándose el plomo del mineral no se pudo realizar ningún muestreo y cuantificación. 


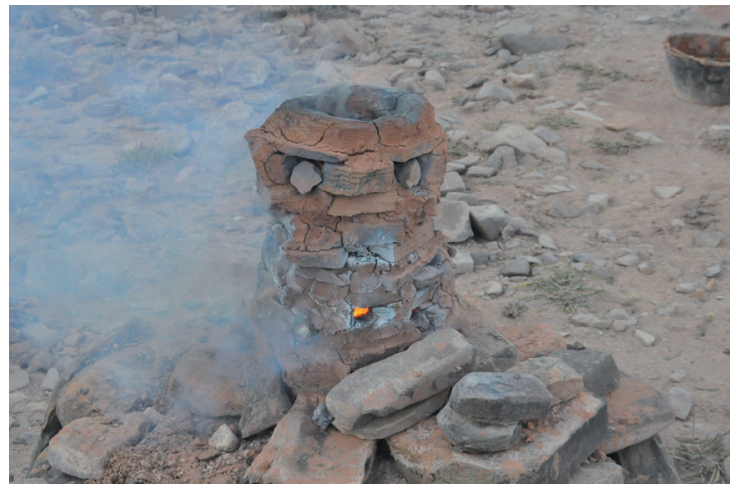

Figura 9. Wayra de piedra (W5) en funcionamiento.

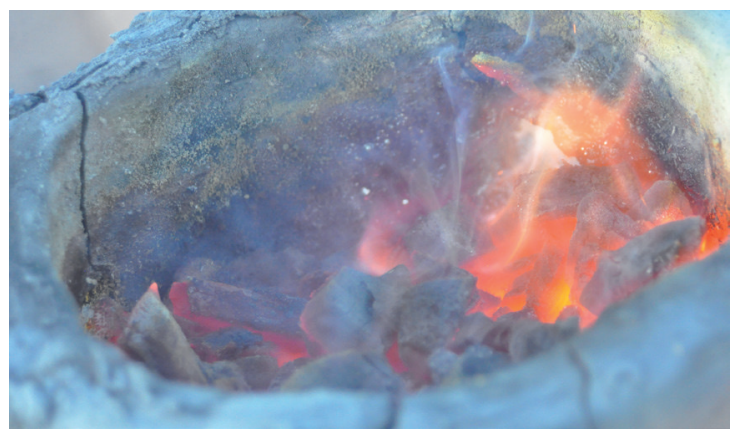

Figura 10. Formación de plomo en el borde de la columna de reducción de la wayra 6

Prueba W2: la prueba W2 fue desarrollada conjuntamente con la prueba W3 el día 20/04. Como la anterior, la puesta en marcha tuvo lugar por la tarde a las 16 hrs 30 , produciéndose desprendimientos solamente en la pared externa del horno. Las cargas de mineral fueron calibradas en un $1 \mathrm{~kg}$ con una granulometría tipo grano de café (Figura 6). Bajo un viento dominante de $6 \mathrm{~m} / \mathrm{seg}$ se introdujo la primera carga a las 17 hrs 30 y las dos otras en intervalos de $10 \mathrm{mi}-$ nutos, constatando la formación de gotas gruesas de plomo cayendo sobre los carbones. La operación fue concluida a las 19 hrs. Después de abrir el horno se constató en el fondo una gran cantidad de gotas de plomo no aglomeradas (403 gr) y una masa de plomo en estado líquido (91 g) (Figuras $7 \mathrm{a}$ y $7 \mathrm{~b}$ ). Se notó igualmente un puente de escoria formado sobre la base de la primera línea de orificios de ventilación. Finalmente, se pudo observar en los carbones inferiores la presencia de mineral poco transformado, así como una escoria cristalizada de coloración gris verdecina.

Prueba W3: el reactor de la prueba $\mathrm{W}_{3}$ fue idéntico al de la prueba $\mathrm{W} 2$, y funcionaron simultáneamente presentan-

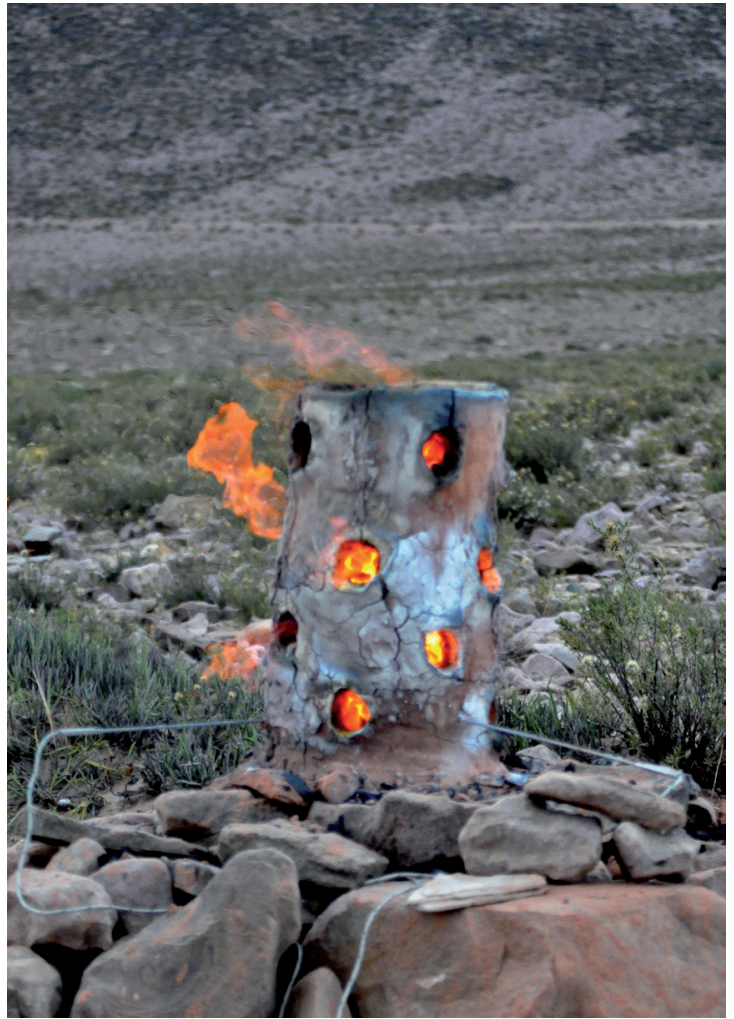

Figura 11. Wayra 7 en funcionamiento con las sondas termocuplas insertadas.

do los mismos problemas de secado. La única diferencia entre ambos estuvo en el mineral procesado: en $\mathrm{W}_{3}$ se depositaron tres cargas de mineral de $1 \mathrm{~kg}$ cada una, pero en estado de polvo. Al final de la operación se pudo constatar el que el mineral se concentró en el fondo del horno donde la temperatura resultó demasiado baja para que se efectuase la transformación. Asimismo se pudo constatar durante la operación una mayor emanación de gases de sulfato de plomo, característica de las fases de quemado y no de reacción y reducción.

Prueba W4: la prueba comenzó a las 16 hrs 30 el día $22 / 04$ con un viento entre 6 y $8 \mathrm{~m} / \mathrm{seg}$. A los 20 minutos de la puesta en marcha, el horno alcanzó una temperatura de $360{ }^{\circ} \mathrm{C}$ (bajo el viento) y $276{ }^{\circ} \mathrm{C}$ (contra el viento). A las $17 \mathrm{hrs}$ las sondas mostraron una diferencia de temperatura más acentuada, $720^{\circ} \mathrm{C}$ contra $314{ }^{\circ} \mathrm{C}$, confirmando el importante gradiente térmico en el interior del horno (Figura 8). Esta diferencia, junto al secado mediocre condujo a roturas de la pared. Solamente en el lado expuesto al viento éstas no cedieron. Una vez reparadas las paredes, 


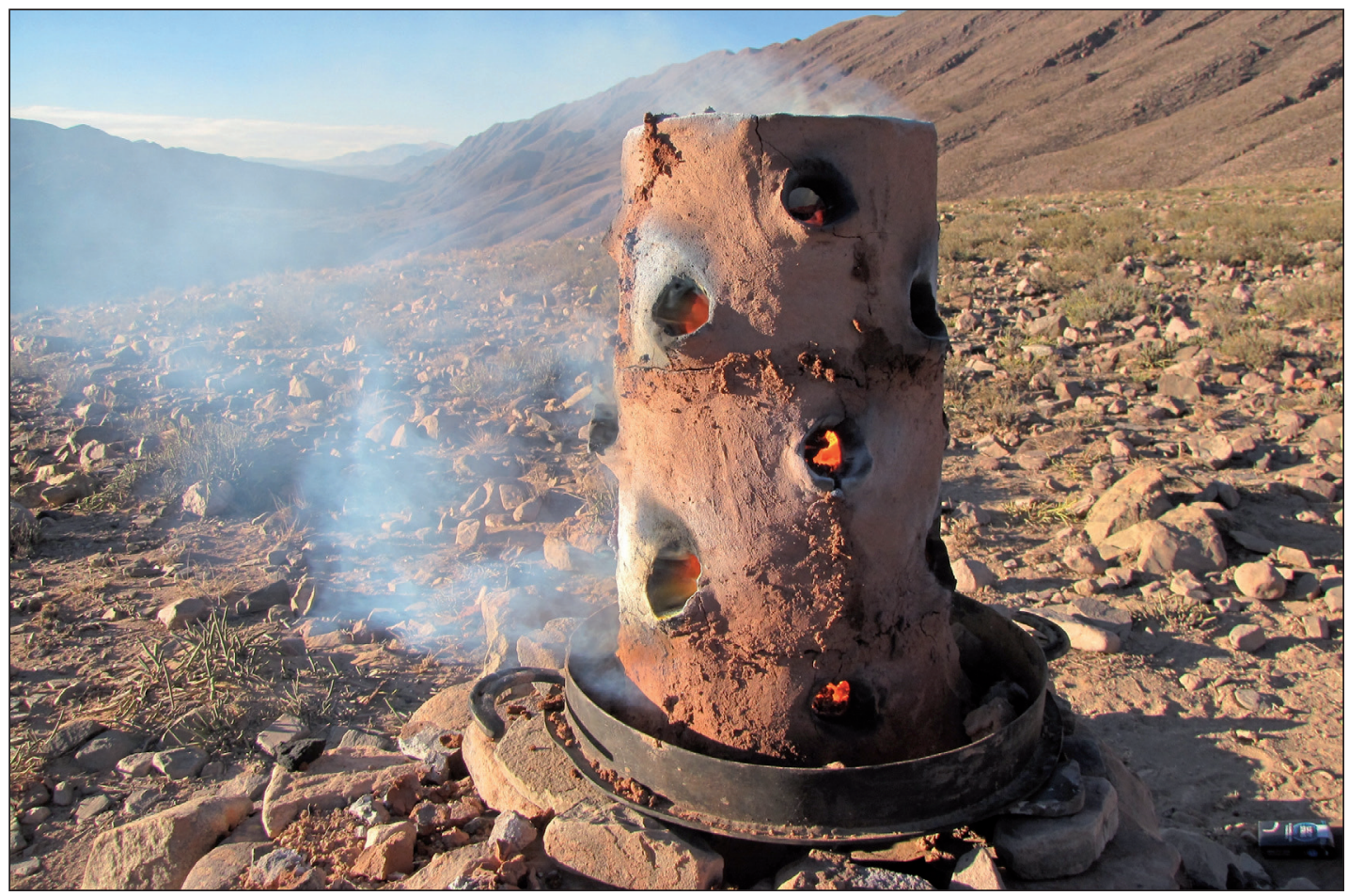

Figura 12. Wayra 8 (construida sobre plataforma de hierro) en funcionamiento.

se depositó a las 17 hrs 20 una carga de mineral de $1 \mathrm{~kg}$, teniendo en ese momento temperaturas de 930 y $400{ }^{\circ} \mathrm{C}$. Se pudo constatar, por los orificios de ventilación expuestos al viento, la formación de gotas gruesas de plomo, así como el comienzo del proceso de escorificación de la pared. La reacción fue muy rápida, y a las 17 hrs 30 se procedió al depósito de la segunda carga bajo temperaturas de $913{ }^{\circ} \mathrm{C}$ y $500{ }^{\circ} \mathrm{C}$. La última carga fue depositada a las $17 \mathrm{hrs} 45 \mathrm{con}$ $950^{\circ} \mathrm{C}$ y $480{ }^{\circ} \mathrm{C}$ de temperatura. Entre cada carga se llenó la columna del horno con carbón a fin de favorecer tanto la reacción como el mantenimiento de la temperatura. $\mathrm{La}$ prueba concluyó a las $19 \mathrm{hrs}$, recuperando del fondo del horno una pequeña concentración de plomo (14 gr) y un producto plomífero (93,4 gr). De la misma manera que las pruebas anteriores, un puente con escoria comenzó a formarse bajo la primera línea de orificios expuestos al viento. Prueba W5: se trató de una prueba única ya que el reactor fue construido con piedras unidas con argamasa de arcilla (Figura 9), razón por la cual se decidió no instrumentar el horno. Las fuerzas del viento fueron idénticas a la prueba $\mathrm{W}_{4}$ dado que los dos hornos funcionaron de manera simultánea. La carga de $3 \mathrm{~kg}$ fue repartida en tres lotes del mismo peso a partir de las $17 \mathrm{hrs} 15$, con intervalos de 15 minutos. El dato más importante fue que el horno consumió el doble de carbón que $\mathrm{W}_{4}$ no logrando una transformación de plomo.

Prueba W6: el día 23/04 se reutilizó la wayra usada en la prueba $\mathrm{W}_{4}$, poniéndola en funcionamiento a las $16 \mathrm{hrs}$ 45 con un viento de $4-6 \mathrm{~m} / \mathrm{seg}$. Las temperaturas aumentaron regularmente a medida que se llenaba el reactor con carbón. Cuando el horno estuvo lleno, las sondas indicaron $1000^{\circ} \mathrm{C}$ y $430{ }^{\circ} \mathrm{C}$, es decir una importante diferencia térmica como en $\mathrm{W}_{4}$. Una primera carga de $1 \mathrm{~kg}$ de mineral fue vertida a las 17 hrs 30 bajo temperaturas de $1050^{\circ} \mathrm{C}$ y $570{ }^{\circ} \mathrm{C}$. La segunda carga tuvo lugar a las 17 hrs 45 con temperaturas de $860^{\circ} \mathrm{C}$ y $580^{\circ} \mathrm{C}$, constatándose gotas visibles de plomo en las tres líneas de orificios superiores y en las paredes (Figura 10). La última carga fue depositada a las $18 \mathrm{hrs}$ con un viento variable entre 3 y $7 \mathrm{~m} / \mathrm{seg}$ y una temperatura entre $960{ }^{\circ} \mathrm{C}$ y $560{ }^{\circ} \mathrm{C}$. Entre las $18 \mathrm{hrs}$ y $18 \mathrm{hrs} 45$ las temperaturas descendieron sustancialmente, pero reduciendo la diferencia térmica entre $752{ }^{\circ} \mathrm{C} 490{ }^{\circ} \mathrm{C}$. A las 19 hrs se concluyó la prueba en razón de la temperatura descendiente. 
Prueba W7: esta prueba se realizó el día 24/04, reutilizando la misma wayra 4 . Si bien las paredes presentaban fisuras, el reactor pudo servir a la operación sin necesidad de reparación alguna. La puesta en funcionamiento del horno tuvo lugar a las $17 \mathrm{hrs}$ con un viento de 1 a $3 \mathrm{~m} /$ seg, llevando más de 1 hora poder aumentar la temperatura. La primera carga fue introducida a las $18 \mathrm{hrs} \mathrm{con} \mathrm{un}$ viento creciente de $4 \mathrm{~m} / \mathrm{seg}$ y una temperatura de $997^{\circ} \mathrm{C}$. Un cuarto de hora más tarde, la velocidad del viento cayó a 2-3 $\mathrm{m} /$ segundo, evidenciado solamente en un orificio la presencia de carbones en estado de "blanco refulgurante". Asimismo, se constató la formación de plomo procedente de minerales pegados a la pared como producto de las pruebas anteriores, así como una fuerte producción de sulfato de plomo que se concentró en la pared exterior y en la boca del horno (Figura 11). La escasa velocidad del viento no permitió la introducción de ninguna carga de mineral, concluyendo prematuramente la prueba.

Prueba W8: el objetivo de la prueba fue corroborar la versatilidad de una wayra portátil (Figura 12). Antes de su traslado y puesta en funcionamiento con mineral, la wayra fue calentada de manera progresiva hasta alcanzar una temperatura de $600{ }^{\circ} \mathrm{C}$, sin ocasionar ninguna fisura ni rotura en las paredes. El traslado de la wayra fue efectuado tres días después, el 21/06, sin presentar ningún problema. El ensayo tuvo lugar a las $17 \mathrm{hrs}$ bajo un viento entre 7 y $8 \mathrm{~m}$. La temperatura del horno aumentó muy rápidamente, alcanzando los $1150{ }^{\circ} \mathrm{C}-1200{ }^{\circ} \mathrm{C}$, lo cual produjo importantes fisuras a nivel de las juntas de los panes de arcilla. A las 17 hrs 30 se efectuó la primera carga de $1 \mathrm{~kg}$ de mineral, y las dos restantes seguidas por un intervalo de 15'. Como en los casos anteriores se observaron gotas de plomo discurrir por los carbones y las paredes internas expuestas al viento, aunque no se recuperó del fondo del horno una cantidad de plomo tan significativa como en W2. El principal dato obtenido en esta prueba fue comprobar la versatilidad de la wayra portátil para adecuarse rotando su eje según la dirección del viento dominante en las horas de trabajo, siendo esta su principal ventaja y no tanto su desplazamiento de un lugar a otro.

\section{* Discusión}

Los rendimientos observados, en término de obtención de plomo, muestran una buena maestría del procedimiento de fundición, aunque incompleta, en las pruebas
W2, W4, W6 y W8. En los casos de W2, W6 y W8, el rendimiento se establece en un 15\%, una estimación a mínima ya que se consideró el mineral en estado puro. Las pruebas realizadas permitieron obtener un dato fundamental en relación con las observaciones realizadas en sitios metalúrgicos de Potosí y Porco. En ellos se pudo registrar la presencia de mineral procesado con un tamaño que oscila entre un grano de café y la gravilla. Mientras que los hornos de reducción europeos de estos mismos tamaños no soportan minerales en granos finos y polvo, las wayras parecen haber funcionado únicamente con minerales triturados en granos groseros. Existe evidentemente una relación estrecha entre el tamaño del combustible y el de la materia a fundir, pero forzando la comparación con el modelo europeo, se asevera que en los dos casos se utilizaron carbones del mismo tamaño. Se trata de una diferencia notoria que impacta en la fase de preparación de los minerales y que no formó en ningún momento parte de las costumbres metalúrgicas europeas.

Como fue dicho antes, el nombre vernáculo de este tipo de hornos hace referencia al viento. Se trata, junto al carbón y al mineral, de un elemento esencial en este tipo de metalurgia. La importancia del viento se pone en evidencia en el hecho de que se logró producir plomo en una zona con un déficit de aire cercano al 30\%. El suceso de las operaciones $\mathrm{W}_{2}, \mathrm{~W}_{4}$, W6 y W8, así como los resultados fallidos en las otras pruebas, en particular $\mathrm{W}_{7}$, tuvieron más que ver con la velocidad del viento que con el tamaño fijado del mineral. Resulta así probable que por debajo de un viento de $6 \mathrm{~m} / \mathrm{seg}$ no se pueda lograr una producción correcta y eficiente de plomo. Este dato se correlaciona con las observaciones realizadas anteriormente en la plataforma de Melle, donde la velocidad del viento (artificial) no pasó nunca este límite, a pesar de contar con un 100\% de aire. Queda aún por demostrar que a medida que se incrementa la altura y se rarifica el aire se vuelve necesario trabajar, o no, con vientos más fuertes. En estas pruebas se logró realizar la metalurgia extractiva de mineral de galena con vientos entre 6 y 9 $\mathrm{m} / \mathrm{seg}$, mientras que en sitios metalúrgicos de Potosí, situados sobre los $4000 \mathrm{~m}$, las wayras fueron sometidas a vientos de 18 a $21 \mathrm{~m} / \mathrm{seg}$ en un ambiente empobrecido en aire en torno a un $40 \%$. En todo caso, para comprender el funcionamiento correcto de las wayras, no resulta evidente que la relación entre el porcentaje de aire y la velocidad del viento sea lineal. 
Otro elemento notorio, probablemente relacionado con el sistema de ventilación, es la rapidez que tuvieron las operaciones de piro-metalurgia. En total fueron necesarias dos horas para transformar $3 \mathrm{~kg}$ de mineral. En los casos de hornos de reducción del mismo volumen, pero con ventilación forzada, fueron necesarias $3 \mathrm{hrs} \mathrm{de}$ funcionamiento para consumir $2 \mathrm{~kg}$ de mineral. En otra formulación, en el caso de las wayras el ratio masa (kg)/ tiempo (h) resulta de 1,5 mientras que en los hornos con ventilación forzada es de o,66. Es decir, en las pruebas realizadas en estos dos tipos de hornos, la ventilación natural expuso un mayor nivel de eficacia en economía de combustible ya que el tiempo de calentamiento en masa constante es reducido en más de un factor 2. Una economía de combustible que se incrementa aun más dado que este tipo de hornos trabaja en fases de quemado (roasted) y reacción, y no en fases de quemado y reducción (Schnabel 1896).

La formación de un puente, mezcla de escoria y de mineral no completamente transformado, sistemáticamente por debajo de la última línea de orificios de ventilación indica que este modelo de wayra puede ser mejorado. En efecto, estos puentes demuestran que la parte inferior de los hornos no alcanzaron la temperatura necesaria para que las escorias y otros materiales, a excepción del plomo, hayan fluido hasta el fondo de los mismos. Esta condición podría minimizarse descendiendo la última línea de orificios de ventilación a la altura del fondo de los hornos.

Por otro lado, las observaciones realizadas en la prueba W5 no acompañan las informaciones coloniales acerca de la existencia de wayras construidas en piedra (Capoche 1585), de las cuales se desconocen testimonios arqueológicos. Si bien nada se opone a que un reactor construido con piedras pueda resultar funcional, la prueba realizada muestra un consumo excesivo de carbón sin alcanzar como resultado una producción de plomo. Esto se debe a que sin contar con un encamisado interno, este tipo de hornos no logra conservar óptimamente el calor, y en consecuencia tampoco logra alcanzar los niveles de temperatura necesarios para la transformación de la galena. En ese sentido, es posible que Capoche y otros autores hayan incluido dentro de la categoría "wayra" a otras estructuras de combustión metalúrgicas, en este caso construidas con piedras, diferentes a las wayras más generalizadas que fueron construidas con arcillas. La inclusión de estas estructuras de combustión en piedra dentro de la categoría de las "wayra" estaría plenamente justificada al funcionar igualmente gracias a la acción del viento. De hecho, estructuras metalúrgicas construidas en piedra muy diferentes a las wayras aquí tratadas fueron identificadas en sitios prehispánicos como Alianza y Saitoco en la región Intersalar (Oruro, Bolivia) y en MiñoCollahuasi en el norte de Chile (Salazar et al. 2013: 31). ${ }^{16}$

Finalmente, sobre el transporte y la movilidad de las wayras, sugeridos en las fuentes, la cuestión queda aun abierta. En las pruebas realizadas pudimos constatar que, independientemente de las veces que hayan sido utilizados, los reactores quedan frágiles y mal cocidos, un aspecto que concuerda con las observaciones realizadas en los fragmentos arqueológicos. Si bien es posible desoldar los reactores de las plataformas, su transporte hacia otros espacios resultaría improbable, más aun teniendo en cuenta que la construcción de los hornos en los sitios de fundición no presenta problemas mayores. Diferente resultaría el caso de las wayras construidas sobre un soporte o plataforma móvil, sea este metálico (W8) o en arcilla como señalan algunas fuentes (por ejemplo Barba 1770 [1640]: 134), que no sólo permitiría su desplazamiento sino también regular la orientación del reactor en función de la dirección predominante del viento.

Esta serie de ensayos en wayras constituyen una primera aproximación experimental que necesariamente tiene que completarse con nuevas pruebas que permitan mejorar el rendimiento y alcanzar una reproductibilidad de las operaciones en un mismo contexto ambiental. Por otro lado, es importante que las futuras pruebas experimentales puedan llevarse a cabo en diferentes lugares, incrementando en ello la altura, a fin de poder establecer claramente el rendimiento en relación con la velocidad del viento y la altitud.

Como hemos visto, en la literatura el término wayra, o wayrachina, fue empleado para designar diferentes tipos de estructuras de combustión metalúrgicas, muchas veces mal identificadas. El recurso de la experimentación permite aquí restablecer la relación semántica entre este tipo de horno y su denominación indígena en un siste-

\footnotetext{
${ }^{16}$ Comunicación presentada en el Simposio 5: Arqueología e Historia de la Minería y de la Metalurgia en los Andes del Sur, XVIII Congreso Nacional de Arqueología Argentina.
} 
ma tecnológico y productivo propio a la zona andina que tiene su particularidad en la fuerza del viento, elemento clave en el suceso de las operaciones. Inversamente, los sistemas de ventilación natural conocidos principalmente en la metalurgia del hierro se basan en la advección del aire seguida de su convección en la columna de reducción bajo efecto de la combustión del carbón. En el caso de las wayras andinas, sería principalmente la velocidad del viento lo que asegura la ventilación del reactor posibilitando la transformación del mineral en metal. En síntesis, la aproximación experimental permitió corroborar que, a pesar de la rusticidad y simpleza aparente, las wayras indígenas tuvieron un alto nivel de eficiencia y eficacia en su funcionamiento, además de resultar sorprendentemente económicas en consumo de combustible, un recurso limitado en los paisajes andinos. Se suman a estos aspectos tecnológicos el encantamiento producido por el proceso de producir metales a partir de elementos extraídos de las entrañas de la tierra, las transformaciones sucesivas de los estados de la materia, las emanaciones de luces, colores, olores y sonidos, independientemente del contexto, más cercano a la alquimia cuando no a la magia. No es de extrañar entonces la valoración simbólica que tuvieron los metales en los Andes prehispánicos, ni que, tal como señalara el mercedario Martín de Murúa, las wayras hayan sido objeto de veneración.

\section{* Referencias citadas}

ARDUZ EGUÍA, G. 1997. Sobre la metalurgia colonial de la plata en Potosí, H. y C. 24: 103-134.

BARBA, Á. 1770 [1640]. Arte de los metales. Imprenta del Reyno, Madrid. Copia digital en: Biblioteca El Dorado. Archivo y Bibliotecas Nacionales de Bolivia, Sucre.

BOUYSSE-CASSAGNE, T. 2005. Las minas del centro-sur andino, los cultos prehispánicos y los cultos cristianos. Bulletin de l'IFEA 34.3: 443-462. Lima.

(2008). Minas del sol, del Inka y de la gente. Potosí en el contexto de la minería prehispana. En: Mina y Metalurgia en los Andes del Sur, entre la época prehispánica y el siglo XVII, Cruz, P. y J. Vacher (Eds.), pp. 278-301. IFEA-IRD, Sucre.

CAPOCHE, L. 1959 [1585]. Relación General de la Villa Imperial de Potosí. Biblioteca de Autores Españoles. Ediciones Atlas. Madrid.

CIEZA DE LEÓN, P. 1862 [1553]. La Crónica del Perú. Historiadores Primitivos de Indias, vol. 26. Biblioteca de Autores Españoles. M. Rivadeneyra. Madrid.

COHEN, C., T. REHREN y M. VAN BUREN. 2008. La huayrachina por dentro y por fuera: un estudio arqueo-metalúrgico de la tecnología de fundición de plomo en Porco-Potosí, Bolivia. En: Mina y Metalurgia en los Andes del Sur, desde la época prehispánica hasta el siglo XVII, P. Cruz y J. Vacher (Eds.), pp. 29-56. IRD-IFEA. Sucre.

CRUZ, P. 2010. Tumbas, metalurgia y complejidad social en un páramo del altiplano surandino. Pulacayo, Bolivia, primer milenio d.C. Revista Andina 49: 71-104. Cuzco.
2009. Huacas olvidadas y cerros santos. Apuntes metodológicos en torno a la cartografía sagrada en los Andes del sur de Bolivia (Potosí, Chuquisaca). Estudios Atacameños 38: 55-74. San Pedro de Atacama.

CRUZ, P. y P. ABSI. 2008. Cerros ardientes y huayras calladas. Potosí antes y durante el contacto. En: Mina y Metalurgia en los Andes del Sur. Desde la época prehispánica hasta el siglo XVII, Cruz, P. y J. Vacher (Eds.), pp. 91-121. IRD-IFEA, Sucre.

DE NIGRIS, M. y O. PUCHE RIART. 2011. El uso de los hornos pachamanca y guayra para la fundición en los Andes. De Re Metallica 16: 21-31. Sociedad Española Para la Defensa del Patrimonio Geológico y Minero. Madrid.

ESCOBARI DE QUEREJAZU, L. 2011. Mano de obra especializada en los mercados coloniales de Charcas. Bolivia, siglos XVI-XVII. Nuevo Mundo, Mundos Nuevos. Debates. Mascipo, París. http:// nuevomundo.revues.org $/ 60530$

FUENTE SANCT ÁNGEL, R. de la. 1965 [1572]. Relación del cerro de Potosí y su descubrimiento. En: Relaciones geográficas de Indias Vol. II. M. Jiménez de la Espada (Comp.):357-361. Biblioteca de Autores Españoles. Madrid.

GARCILASO DE LA VEGA, I. 1992 [1603]. Comentarios Reales de los Incas. Biblioteca Ayacucho. Caracas.

LECHTMAN, H., P. CRUZ, A. MACFARLANE y S. CARTER. 2011. Procesamiento de Metales durante el Horizonte Medio en el Altiplano Surandino (Escara, Pulacayo, Potosí). Boletín del Museo Chileno de Arte Precolombino 15 (2): 9-27. Santiago. 
MURÚA, M. DE. 2004 [1590]. Códice Murúa: Historia y Genealogía de los Reyes Incas del Perú del Padre Mercenario Fray Martín de Murúa: Códice Galvin. J. M. Ossio A. (Ed). Testimonio Compañía Editorial. Madrid.

NIEMEYER, H. 1986. La ocupación incaica de la cuenca alta del río Copiapó (III Región de Atacama, Chile). Comechingonia. Número Especial: 165-294. Córdoba.

NIEMEYER, H., M. CERVELLINO y E. MUÑOZ. 1983. Viña del Cerro, expresión metalúrgica inca en el valle de Copiapó. Creces 4(4): 50-57. Santiago.

OEHM, V. 1984. Investigaciones sobre minería y metalurgia en el Perú prehispánico. Bonner Amerikanistische Studien 12. Bonn.

PEELE, R. 1894. A primitive smelting furnace. The School of Mines Quarterly, Vol. XV: 8-10.

PETERSEN, G. 1970. Minería y Metalurgia en el Antiguo Perú. Arqueológicas 12. Museo Nacional de Arqueología y Antropología. Lima.

RAFFINO, R., R. ITURRIZA, A. IÁCONA, A. CAPPARELLI, D. GOBBO, V. MONTES y R. VÁSQUEZ. 1996. Quillay. Centro metalúrgico Inka en el Noroeste Argentino. Tawantinsuyu 2: 5969. Camberra-La Plata.

SALAZAR, D., J. BERENGUER y G. VEGA. 2013. Paisajes minerometalúrgicos en Atacama y el altiplano sur de Tarapacá (norte de Chile). Chungara Revista de antropología chilena 45(1): 83-103. Arica.

SAlAZAR, D., B. Mille, V. FigUeroA, F. BALESTRO, C. PERLÉS, J. BERENGUER, D. BOURGARIT, P. CORRALES, L. CARROZA y A. BURENS. 2013. Metalurgia indígena en el distrito Miño-Collahuasi, norte de Chile (siglos X a XVII): tec- nología y organización de la producción de cobre. Arqueología Argentina en el Bicentenario de la Asamblea General Constituyente del año 1813. Actas del XVIII Congreso Nacional de Arqueología Argentina. INCIHUSA-CONICET. La Rioja.

SCHNABEL, L. 1896. Traité théorique et pratique de Métallurgie Cuivre - Plomb - Argent - Or, traduit de l'allemand par le Dr. L. Gautier. Baudry et Cie. París.

TÉREYGEOL, F. y C. CASTRO. 2008. La metalurgia prehispánica de la plata en Potosí. Mina y Metalurgia en los Andes del Sur. Desde la época prehispánica hasta el siglo XVII, Cruz, P. y J. Vacher (Eds.), pp. 11-28. IRD-IFEA, Sucre.

TÉREYGEOL, F. y P. CRUZ. 2012. Die Silberberwerke von Potosi: Das wichtigste Technologiezentrum Südamerikasaus der Sicht der Autoren der Inkaund der Spanier. Der Anschnitt 64: 93-108. Bochum.

TÉREYGEOL, F. y P. CRUZ. 2012. Huayrachina. Un horno de fundición andino, para minerales metálicos no ferrosos de los Andes. En: Tesoros de los Andes, cobre chileno para el mundo, Slotta R., Schnepel I. (Eds.), Bochum.

TÉREYGEOL, F. 2009. Programme Collectif de Recherche : paléométallurgies et expérimentations. Service Régional de l'Archéologie Poitou-Charentes.

VAN BUREN, M. y B. MILLS. 2005. Huyarachinas and tocochimbos : traditional smelting technology of the southern Andes, Latin American Antiquity 16(1): 3-25.

VAN BUREN y C. COHEN. 2010. Technological changes in silver production after the spanish conquest in Porco, Bolivia. Boletín del Museo Chileno de Arte Precolombino 15(2): 29-46. Santiago. 